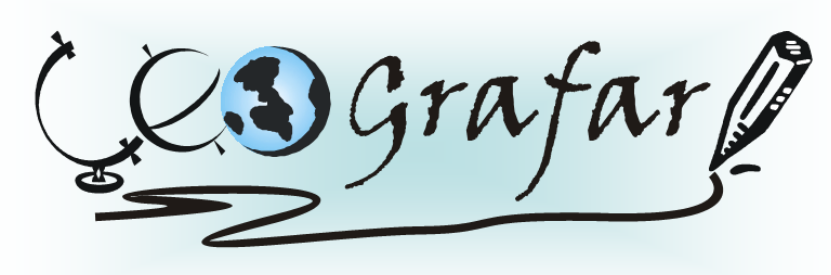

Revista Eletrônica do Programa de Pós-Graduação em Geografia - UFPR

\title{
RUMO A PÓS-MODERNIDADE: A VIRADA LINGUÍSTICA NA GEOGRAFIA. VIRADA LINGUÍSTICA?
}

\section{NEIDE DE MOURA ${ }^{1}$}

RESUMO: No início dos anos 1970, as ciências sociais se vêem "vítimas" de uma "virada" em seu modo de pensar, agir e "falar". As diferentes linguagens (aqui entendidas como signos) colocam-se como outra opção, outra "forma", não no sentido literal da palavra, mas sim no sentido de diferença, de mudança substancial em sua essência. Trata-se da virada lingüística que assume diferentes posturas e modos de "fazer ciência". .A Geografia, em seu viés de ciência social, inclui em seu corpo marcas, rastros que foram deixados e aos poucos, incorporados por esta nova postura em relação aos fatos, em relação aos modos pelos quais se realiza enquanto ciência. Assim, no âmbito da chamada abordagem Humanista de Geografia incorporam-se os estudos do mundo vivido, das religiões, das ideologias que podem trazer subsídios de análise geográfica, enquanto que a Geografia Crítica incorpora estudos de cunho idealista. No decorrer das linhas que se sucedem à tentativa por uma elucidação do que seria a "virada lingüística" nos estudos de geografia se fará presente, buscando ser também pertinente para a compreensão das possibilidades e debates atuais que têm como foco à virada lingüística na geografia, fazendo um paralelo entre o presente, o passado e o futuro das bases conceituais da geografia, sobretudo, a geografia cultural.

Palavras - chave: cultura, pós-modernidade, virada lingüística.

ABSTRACT: In the early 1970, the social sciences are "victims" of a "turnaround" in its way of thinking, acting and "talking". The different languages (here construed as signs) pose themselves as another option, another "," not in the literal sense of the word, but in the sense of difference, of substantial change in its essence. It is the linguistic turn that takes different postures and ways of "doing science." Geography, in his bias, social science, includes in his body marks, footprints that were left and slowly, incorporated by this new posture in relation to the facts, in relation to the ways in which takes place as a science. Thus, under the call of Geography humanistic approach incorporates up studies of the world lived, of religions, of ideologies that can bring subsidies geographic analysis, while Geography Book incorporates studies of embossing idealistic. During the lines which follow an attempt by an elucidation of what would be the "linguistic turn" in the studies of geography will be present, seeking also be relevant for the understanding of the possibilities and current debates that have a focus on the linguistic turn in geography, making a parallel between the present, past and future of the conceptual basis of geography, especially the cultural geography.

Keywords: culture, post-modernity, linguistic turn.

\begin{abstract}
“A linguagem é o modo primário da comunicação humana, constituidora da própria individualidade daqueles que a utilizam. Por essa razão, os geógrafos culturais (...) têm-se dedicado cada vez mais ao papel simbólico da linguagem em nossas relações com o mundo natural, a ponto de considerarem a paisagem cultural como um texto". (Denis Cosgrove)
\end{abstract}

\footnotetext{
${ }^{1}$ Mestranda em Geografia. Universidade Federal do Paraná. neidedemoura@ hotmail.com
} 


\section{INTRODUÇÃO}

As necessidades de mudança, de rupturas rumo a novas leituras do mundo, induzem as ciências modernas, dentre as quais se encontra a geografia, a encontrar e desenvolver diferentes possibilidades para o estudo do mundo, que teve suas bases modificadas após a explosão desenvolvimentista do período pós-guerra.

O período em questão é o final dos anos 1960 e início dos anos 1970, fase em que as novas tecnologias chegam aos mercados e, pouco a pouco, invadem as casas dos consumidores.

No meio geográfico, em ambas as suas vertentes (física e humana) surgem também as primeiras e inquietantes propostas de mudança com o intuito de que as novas faces do mundo pudessem ser explicadas geograficamente. Segundo Soja (1993, p. 20) tais inquietações "mal se fizeram ouvir no alarido temporal vigente", fazendo com que os debates mais profundos fossem adiados.

Foram necessárias quase duas décadas para que o fenômeno pós-moderno ganhasse corpo e força com pensadores de dentro e fora da geografia com nomes como Foucault, Lefebvre, Berger e Mandel considerados por Soja (1993, p. 78) os fundadores do pósmodernismo.

Mas, onde entra afinal, a virada lingüística neste contexto? Numa tentativa de encontrar caminhos para a explicação das diferentes formas que se construíram concomitantemente ao pós-modernismo, no qual culturalmente falando, 'nada se cria, tudo se incorpora', é que se coloca a necessidade de um estudo que dê conta da explicação das inúmeras linguagens surgidas no contexto vigente.

Tal necessidade se coloca como um caminho que busca a explicação das linguagens do mundo pós-moderno, juntamente com a cultura daqueles que a utilizam. Segundo Berger (1984) é necessário conhecer os homens e mulheres tal como são no mundo, com suas desigualdades, para só então, se poder realizar uma narrativa do espaço, "qualquer narrativa contemporânea que ignore a urgência dessa dimensão é incompleta e adquire o caráter super simplificado de uma fábula” (BERGER, 1984 apud SOJA, 1993, p. 31). 
Neste contexto, a virada lingüística se colocou a disposição, porém, olhares de reprovação povoam as críticas a ela destinadas. Mas, um fato não pode ser negado: internet, globalização, pinturas, obras literárias (...) apresentam-se concretamente como fontes para os estudos geográficos, sobretudo os humanos.

No decorrer deste, se tentará realizar uma explanação a cerca do pós-modernismo e a virada lingüística na geografia, sobretudo no que concerne aos estudos humanos e culturais.

\section{O COMEÇO DO FIM: assumindo e experimentando}

O final dos anos 1960 e inicio dos anos 1970, ficaram marcados por uma enorme vontade de romper com antigos paradigmas da ciência clássica positivista, pelas ciências de um modo geral.

Não foi diferente com a geografia. Durante o período em questão houve mudança e quebra profunda de paradigmas, ou pelo menos com tal intenção.

Os velhos arcabouços teórico-metodológicos foram aos poucos abandonados, porém continuavam a existir paradigmas, o que colocava apenas uma mudança e não uma resolução.

Para Claval (1999, p. 60) o declínio da geografia tradicional, em especial a geografia cultural, tem início nos anos 1950, se estendendo pelas duas décadas seguintes. Como explicação para tal acontecido, o autor cita três razoes:

1- $\quad$ Falava-se de cultura, contudo não eram levados em conta, pontos essenciais como as representações, opiniões e crenças;

2- Os estudos culturais baseados em artefatos perdem sua validade, à medida que as técnicas se desenvolvem fazendo com que os utensílios diminuam em diversidade ou até desapareçam completamente;

3- As diversidades de atividades encontradas nas cidades fazem com que a descrição dos gêneros de vida perca sua validade. (op. cit. p. 61).

Uma tentativa, um salto por assim dizer é dado na geografia com as iniciativas de suas abordagens Humanista e Crítica, em direção a resolução e rompimento com paradigmas. A necessidade de contrapor pensamentos, de expor novas possibilidades em relação à situação 
colocada pela geografia quantitativa, serviu de impulso para que novas atitudes de mudança e transformação ganhassem corpo no meio geográfico.

Nas palavras de Claval (1999, p. 63) a rápida evolução científica juntamente com as críticas ao pensamento positivista contribuiu significativamente para o avanço epistemológico das ciências, em especial a geografia. Os geógrafos percebem que "os homens, os grupos e os lugares são realidades variáveis" e que, portanto, merecem ser estudados com maior rigor e profundidade, respeitando sua natureza "material, histórica e geográfica" (op. cit. p. 63).

De acordo com Relph (1976) durante a década de 1970, a geografia Humanista levantou argumentos que procuravam dar integridade e autenticidade ao lugar, recorrendo para tanto "às críticas da sociedade moderna feitas pela Escola de Berkeley" (COSGROVE \& JACKSON, 2003, p. 137). Entretanto, tais argumentos eram rasos e acabavam por suprimir aspectos relevantes da "diferenciação cultural e ecológica" (op. cit. p. 138).

O rumo que se dá nesta perspectiva vai de encontro aos significados dos signos surgidos meio aos novos parâmetros mundiais que emergiam fortificados pelo poder das mídias, modificando culturas e identidades; criando e recriando maneiras de ver o mundo.

Os signos e seus significados se constituem na palavra-chave desta nova proposição. A imaginação dá significado ao mundo humano, permitindo que o homem a transforme e crie significados para suas ações, através da linguagem. Entretanto, os argumentos e propostas da abordagem Humanista não conseguiram se sustentar por muito tempo. Pautada demasiadamente no corpo humano, nos sentidos e suas relações com o mundo exterior, esquece-se de verificar as coletividades e seu agir diferenciado. Por este e outros motivos, os rumos propostos por esta abordagem acabaram sendo aos poucos abandonados.

\section{O FIM DO COMEÇO: em busca de novos horizontes}

No início dos anos 1990, pode-se observar a crescente busca pelos novos rumos estabelecidos para a geografia. As linguagens estão presentes em toda a parte, a geografia também (COSGROVE, 1998). Faz-se necessária a retomada da virada lingüística iniciada nos anos 1970. Porém, com enfoque que agora requer a contextualização dos signos que se apresentam ao estudo do geográfico. De acordo com Corrêa (1999, p. 49) tal retomada inicia- 
se na década de 1990, sobretudo na geografia cultural, por meio de periódicos especializados que muito contribuíram para o desenvolvimento que se fazia necessário.

Amaral Jr. (2005, p. 72) ressalta que "a noção de experiência sofre um deslocamento significativo nas ciências sociais a partir da chamada virada lingüística". Parafraseando o autor, pode-se dizer que a cultura de um modo geral foi deslocada do rumo estabelecido nas décadas de 1960 e 1970.

Neste sentido, Sahr (2006), coloca que o mundo assistiu nos anos 1990, a um turbilhão de imagens carregadas de significados inseridos nos parâmetros tecnológicos que se faziam presentes. Abrem-se então, novos horizontes, novas possibilidades para a geografia que encontra, por sua vez, na linguagem arcabouço teórico-metodológico para estudá-la.

Mesmo direcionamento é dado por Claval (1999, p. 62-63) quando menciona as evoluções e revoluções do mundo atual e o posicionamento dos geógrafos frente a isto. Para o autor "a única maneira de a geografia levar em consideração os novos preceitos epistemológicos é adotar uma abordagem cultural” (op. cit. p. 63). Para o presente artigo, o ponto central não é colocar uma posição de superioridade para a geografia cultural, mas sim destacar seu valor face aos novos parâmetros sociais, políticos e econômicos que se mostram instigantes aos estudos geográficos, bem como mostrar e tentar validar a lógica lingüística para suas análises.

Cosgrove (1998, p. 116) menciona que o simbolismo impresso nas diferentes culturas permite ao geógrafo refletir sobre si mesmo e sobre a geografia humana que pretende desenvolver. Continuando, afirma que é necessário, acima de tudo, "uma sensibilidade histórica e conceitual por parte do geógrafo" (op. cit. p. 110) e que para tanto "a linguagem é crucial" (op. cit. p. 110).

As imagens e as linguagens presentes na atualidade passaram a se constituir em "enigmas para a perspectiva contemporânea" (COSGROVE \& JACKSON, 2003, p140) bloqueando o entendimento do mundo; o que gerou, na visão dos autores citados, uma crise entre significado e método, passando de uma 'janela transparente' para uma 'janela opaca' de observação, que tem a capacidade de enganar o pesquisador, através de suas manifestações de um "processo de mistificação e ideologia" (op. cit. p. 110).

Ainda citando Cosgrove \& Jackson (2003) é apontada como explicação para tal fato a complexidade expressa pelo mundo pós-moderno que se vê 
marcado pela liberdade de atribuir significados e pela intertextualidade, com a qual invertemos signos e símbolos para recriá-los em contextos diversos, dessa forma, transformar sua referência _ enfatiza a superfície e não a profundidade (op. cit. p. 140).

Entretanto, os métodos que se utilizam a "interpretação em profundidade" são raros nos estudos das paisagens contemporâneas. (op. cit. p. 140).

Para Duncan (2004, p. 94) os estudos interpretativos e literários, até muito recentemente se encontravam distante do meio geográfico. Em seu pensamento sobre o assunto, coloca que

os profissionais ficavam indiferentes ao desenvolvimento das ciências sociais ou das humanidades _ com que Lévi-Strauss, Derrida ou Michel Focault, poderia ter a dizer a respeito dos processos culturais ou da representação _ sob a alegação de que os interpretes da paisagem não precisam se preocupar com debates esotéricos.

Os debates no entorno da linguagem como abordagem para a interpretação da paisagem cultural (assim entendida por alguns) pode conduzir a uma visão interdisciplinar na qual as discussões sobre representação, consciência, ideologias, enfim, as diferentes possibilidades inerentes a um sistema cultural encontram-se como linhas paralelas, caminhando juntas em busca de uma melhor maneira de interpretar a cultura.

\section{ENTRE O MODERNO E PÓS-MODERNO: alguns apontamentos}

Em busca de uma comparação entre o que poderia ser considerado moderno e pósmoderno Rogério Haesbaert propõe em seus Territórios Alternativos (2002, p. 37) um quadro comparativo entre os dois movimentos, transcrito a seguir:

Em seu livro, Haesbaert (2002) contesta com firmeza a existência de um período pósmoderno, citando autores que vão de encontro ao seu pensamento. Não caberia no âmbito de um artigo a discussão entre a existência ou não da pós-modernidade, o que se pretende é justificar a virada lingüística, inserindo-a no contexto atual vigente.

Assim sendo, o fato é que para o presente texto, o quadro comparativo de Haesbaert (2002) se mostra pertinente, ao passo que demonstra " $n$ " possibilidades aos estudos culturais e que para os quais a virada lingüística pode servir perfeitamente, como base de análise. 


\begin{tabular}{|c|c|}
\hline MODERNIDADE & PÓS-MODERNIDADE \\
\hline $\begin{array}{l}\text { Sociedade industrial } \\
\text { (domínio do setor secundário / proletariado e } \\
\text { burguesia) } \\
\text { Objetividade } \\
\text { (significados padrões) }\end{array}$ & $\begin{array}{l}\text { Sociedade pós-industrial } \\
\text { (domínio do setor terciário / funcionários e } \\
\text { tecnocratas) } \\
\text { Subjetividade } \\
\text { (múltiplos significados) }\end{array}$ \\
\hline Controle, repressão & Jogo (acaso), liberdade \\
\hline $\begin{array}{l}\text { Centralização estatal / macro políticas } \\
\text { (objetivos gerais) }\end{array}$ & $\begin{array}{l}\text { Privatização / micro políticas } \\
\text { (objetivos segmentares) }\end{array}$ \\
\hline Movimentos partidários, "de classe". & $\begin{array}{l}\text { Movimentos setoriais / culturais, } \\
\text { Ecológicos, territoriais }\end{array}$ \\
\hline $\begin{array}{l}\text { Consenso, eficácia } \\
\text { (semelhanças / identidades) }\end{array}$ & $\begin{array}{l}\text { Dissenso, criatividade } \\
\text { (diferenças / ambigüidades) }\end{array}$ \\
\hline Arquitetura uniforme, padronizadora & Arquitetura e arte ecléticas \\
\hline $\begin{array}{l}\text { Racionalidade / teoria } \\
\text { (explicação subordina a paixão à razão) }\end{array}$ & $\begin{array}{l}\text { Sensibilidade / experiência } \\
\text { (sedução, só o impulso e o prazer afirmam a vida). }\end{array}$ \\
\hline
\end{tabular}

O fato de romper com o racionalismo coloca o pós-modernismo numa posição de destaque frente aos ideais modernos, pois se abre espaço para tudo e para todos, transpondo barreiras que antes pareciam impossíveis de serem transpostas.

Não está se dizendo, porém, que o pós-modernismo seja a solução para todas as mazelas da ciência e da humanidade. Apenas se está tentando dimensionar o que pode vir a ser uma transformação com ganhos significativos para o campo científico. O fazer torna-se menos problemático e mais simplificado, mas sem, entretanto, deixar de lado análises profundas e estudo rigoroso. O que muda é a não necessidade de se ter um racionalismo implícito em tudo, fazendo com que a tarefa do cientista seja menos árdua.

Enfim, como diz Claval (1999 b, p. 402) “o movimento pós-moderno recusa o racionalismo que o precedeu (...)" para se transformar no "signo da crise que atinge de repente 
as maneiras de ver o mundo, de definir a verdade e de construir a sociedade que tinha dado segurança aos povos europeus".

\section{RESPONDENDO À QUESTÃO}

Numa tentativa de elucidar os caminhos colocados à geografia humana em sua abordagem cultural, retornamos à pergunta que compõe parte do titulo deste artigo: "virada lingüística?". Da pergunta que não cala a resposta que não fala: a linguagem e seus significados.

Explicar o termo, responder à questão requer pensar nos anseios da geografia cultural rumo a um campo que por muitos ainda não é considerado confiável. Estudar, fazer geografia baseada em signos e significados, em linguagens, não é algo que possa ser encarado como sendo de fácil aceitação pela comunidade científica. Nem mesmo como uma tarefa fácil de ser executada pelos que se dispõe a realizá-la. É preciso explicar a resposta, ou ainda, explicar a explicação dada por outros. Praticar, como diria Fausto Gil², a segunda hermenêutica.

A hermenêutica, utilizada pelos antigos padres da Igreja Católica, é a arte da interpretação dos textos. Realizar a segunda hermenêutica é buscar a interpretação daquilo que as pessoas acham de determinado assunto, tema, objeto, etc., ou seja, usá-la para a interpretação/leitura da cultura impressa nas pesquisas e/ou entrevistas realizadas. Então, pode-se dizer que a Geografia Cultural faz a hermenêutica da hermenêutica, questionando conceitos, fazendo com que os mesmos sejam revistos e, para tanto, a linguagem exerce papel crucial.

Contudo, o mundo atual, globalizado está repleto de diferentes linguagens que se proliferam cada vez mais na medida em que se desenvolve a tecnologia. Com isso, se desenvolvem também diferentes maneiras de conceber, de atuar e de transformar o espaço geográfico. Linguagens são criadas para cada tipo de espaço. Os conceitos ganham significados conhecidos por aqueles que dele fazem uso.

Para estudar esta nova gama de espaços, é necessário que o geógrafo lance mão dos significados que coexistem com estes espaços. Suas linguagens, seus contextos,

\footnotetext{
${ }^{2}$ Palestra proferida em 05/09/2007. Universidade Federal do Paraná. Programa de pós-graduação em Geografia. 
compreendendo que o espaço geográfico se encontra inundado de simbolismos. A este respeito, Isnard (1982 apud CORREA, 2005, p. 294) orienta seu pensamento em relação ao espaço geográfico dizendo que este é também um campo de "representações simbólicas, rico em signos" que tem por meta cumprir a "função social de expressarem as estruturas sociais em suas mais diversas dimensões".

Segundo Correa (2005, p. 294) as formas espaciais dão modelado à cultura: “As formas espaciais, através das quais o simbolismo ganha materialidade, constituem meios através dos quais a cultura é modelada".

Cosgrove (1998, p. 108) também aceita que a paisagem geográfica (assim chamada por ele) "contém um significado simbólico, porque é produto da apropriação e transformação da natureza", onde se encontram impressos por meio da linguagem, "os símbolos, os traços culturais do grupo, ao geógrafo competindo decodificar a paisagem, aprendendo a ler o seu significado" (CORREA, 2005, p. 290) para tanto deve conhecer esta "linguagem". (COSGROVE, 1998, p. 105).

Estes entre outros mais que se poderia citar constituem parte dos apontamentos que se poderiam colocar como justificativa aos estudos lingüísticos inseridos em uma visão pósmoderna, que se mostra de maneira cada vez mais acentuada, mesmo embora seus fundamentos ainda sejam alvo de críticas e debates. Mas, se não existirem debates, não existe avanço científico. A superação é necessária.

\section{TRILHANDO NOVOS CAMINHOS}

A virada lingüística coloca novos rumos, novos caminhos a serem trilhados.

O espaço simbólico dos jogos de criança e seu uso imaginativo de lugares-comuns para criar paisagens de fantasias, o local da caravana cigana, as marcas deixadas por mendigos (...), o grafite das gangs de rua (...). é fascinante comparar os significados oficiais de paisagens do parque público (...) com sua geografia simbólica (...). (COSGROVE, 1998, p. 12).

Estes, entre outros, são alguns dos novos rumos e caminhos que se encontram à disposição do geógrafo interessado em desenvolver trabalhos que levam em consideração os 
significados dos signos que se revelam no meio, na paisagem geográfica. Todos podendo ser englobados pela geografia cultural.

Para Claval (1999, p. 64) a cultura, para os que aceitam a visão pós-moderna, “designa o conjunto de savoir-faire, de práticas, de conhecimentos, de atitudes e de idéias que cada indivíduo recebe, interioriza e modifica ou elabora no decorrer de sua existência”.

Dentre as diferentes maneiras de estudar a geografia cultural entrelaçadas com o movimento da virada lingüística, pode-se citar a pintura, a escrita, os filmes e mesmo as modificações e construções feitas pelos grupos humanos adquirem valor como fonte de informação.

O reconhecimento do valor e do sentido dos signos presentes em diversos elementos do ambiente em que vivemos requer exercícios que fazem necessário o uso de metodologias próprias para o estudo destes temas. Mostram-se eficazes para tal, as de cunho interpretativo e semiótico. A necessidade de decodificar os símbolos das paisagens levou alguns à semiótica, enquanto outros se aventuraram pela análise lingüística, inclusive Tuan buscou na teoria literária e na análise sócio-lingüística bases para ler e decodificar os sentidos das paisagens.

Neste sentido, Cosgrove (1987, p. 137) refere-se a uma "linha interpretativa dentro da geografia cultural recente que desenvolve a metáfora da paisagem como texto, a ser lido e interpretado como documento social".(grifo nosso) Linha semelhante de análise pode ser encontrada nos escritos de James Duncan e sua menção a uma retórica da paisagem, a qual o autor evoca importante distinção quando menciona que "o tema da retórica da paisagem é interessante porque levanta questões sobre os processos por meio dos quais a paisagem é lida como um texto (...)" (DUNCAN, 2004, p. 110. Grifo nosso).

Encarar a paisagem como texto é algo que vem chamando a atenção de geógrafos. Algumas correntes defendem que as paisagens têm um sentido cultural e que podem ser lidas como se fosse um livro, mas é preciso saber ler; dispor dos instrumentos adequados. Contudo, os meios mais precisos de interpretação são encontrados fora da literatura geográfica, como por exemplo, nos estudos sobre estética e semiótica realizados na arquitetura e no urbanismo (FERRARA, 1988; SILVA, 2001).

Como argumento para a pouca contribuição dos geógrafos aos estudos das paisagens como textos, Cosgrove \& Jackson (2003, p. 138) colocam que tal fato se deve a crise que se instaurou em meados dos anos 1980, mas que teve plena configuração nos anos 1990, 
conforme Sahr (2006), das representações nas ciências sociais e, por conseguinte, na geografia humana.

Os estudos culturais contemporâneos vão além do aparentemente observável. Aprofundam-se, para compreender a multiplicidade de culturas existentes, sejam elas antigas ou criadas pelas sociedades pós-modernas. Valendo lembrar que cada uma delas possui suas especificidades de tempo e lugar, abrindo caminho para uma geografia situada na virada lingüística, que dê conta de explicar questões que vão do racismo contra nordestinos no sul do Brasil até as relações políticas existentes no carnaval do Rio de Janeiro.

Mesmo assim, esta nova possibilidade ainda é por muitos mal vista. Esta estranheza com que são vistos os estudos inseridos no âmbito da geografia da virada lingüística não é difícil de ser compreendida, pois as bases de seu pensamento não são fruto direto de nossa disciplina. Nas palavras de Duncan (2004, p. 97) estas bases são pressupostos "híbridos produzidos pelo cruzamento fertilizante de correntes intelectuais tão diversas como a antropologia, a crítica literária e a arte, a psicologia e a ciência política”. Entretanto, pode-se dizer com certa propriedade que estes entre outros, são campos essenciais ao geógrafo cultural que opte por uma compreensão consistente das representações sociais da paisagem.

De acordo com o mesmo autor, a abordagem da interpretação anuncia o abandono da antiga geografia cultural, que pressupunha uma cultura dos artefatos e não do homem enquanto ser social. Tal abordagem direciona três sentidos diferentes a serem seguidos: o primeiro destaca o papel da paisagem nos processos sociais e culturais; o segundo coloca a possibilidade latente do diálogo com as outras áreas do conhecimento; por fim, o terceiro menciona as "questões mais gerais da não-neutralidade teórica e do círculo hermenêutico" que enfatiza pontos como o papel do senso comum nas explicações científicas, por exemplo, (op. cit. p. 98).

\section{NÃO HÁ ESPAÇO PARA PARADIGMAS}

Os caminhos propostos pelo pós-modernismo se mostram obscuros para muitos pesquisadores. Encarar a linguagem e todas as suas possibilidades como um meio pelo qual se irá produzir ciência, estremece as bases teórico-metodológicas que dão sustentação ao mundo acadêmico que se conhece. 
Propor paradigmas é caminhar em sentido oposto ao que propõe o pós-modernismo. $\mathrm{O}$ embasamento pós-moderno evoca o não unitarismo, a quebra de paradigmas tidos como linhas mestras que guiam o pensamento cientifico, sobretudo nas ciências sociais.

Tal discurso coloca o pesquisador numa verdadeira 'saia justa', pois o método deixa de ser o caminho seguro (seja ele qual for: positivista, marxista...) para se alcançar os objetivos da pesquisa, desestabilizando o campo cientifico.

Entretanto, a jornada a ser percorrida inclui um caminho árduo pela frente. As sombras pós-modernas que parecem não obedecer à ordem lógica parecem se direcionar em diversos sentidos, afetando a racionalidade acadêmica, o que para muitos também é um discurso e, como tal, também podem ser vistas como unitaristas, como criadoras de paradigmas. Contudo, esta percepção controversa encontra-se impressa no pós-modernismo que não se preocupa em dar uma direção certa a ser seguida.

O fato é que esta transição vem causando polêmica e tirando o sono daqueles que não vêem a possibilidade de fazer ciência sem a utilização de um método previamente estabelecido e, muitas vezes já comprovado, para dar concretude à pesquisa. Ou ainda, quando se inicia a pesquisa já se sabendo do seu resultado, onde o método é utilizado apenas para a comprovação dos resultados que já se conhecia.

Ora, se já se sabe onde se vai chegar, para que serve a pesquisa acadêmica?

A dúvida paira no ar e na mente daqueles que se vêem perturbados e inquietos pelo pósmodernismo no qual se encontra inserida a virada lingüística, que pode aqui ser comparada a uma 'porta aberta' para o desconhecido: para um leque de possibilidades que se colocam a disposição dos estudos em geografia cultural.

\section{CONSIDERAÇÕES FINAIS}

Em meio às crises existenciais que envolvem a disciplina, mais uma vez encontra-se a geografia com dúvidas e questionamentos, vítima de críticas que visam nada mais senão seu avanço epistemológico. O centro destas críticas e questionamentos gira no entorno do panorama político, econômico e cultural vigente, gerado por uma superação, como proposto por alguns, do modernismo, passando para uma situação chamada de pós-modernismo. 
A passagem para este período requer que sejam repensadas as bases epistemológicas das ciências para que estas se adéqüem à nova realidade, uma vez que esta seja instaurada.

A geografia pós-moderna é desordenada e inquietante, reflexo da crise contemporânea. Em seu interior se encontram crescentes choques entre o velho e o novo, entre o antigo e o moderno. Como argumentos para tal fato se podem apontar a reestruturação da vida atual, que mostra um novo modo de pensar e ver as coisas; a simultaneidade dos acontecimentos e a rapidez com que os mesmos são incorporados pelas massas devem ser levadas em conta no momento em que os pensa cientificamente. (SOJA, 1993).

Segundo Claval (1999, p. 63) "as epistemologias pós-modernas partem de uma análise precisa da maneira pela qual os indivíduos se constroem o que é acompanhado em suas trajetórias individuais".A afirmação do autor confirma a idéia de que as tendências atuais têm de ser levadas em conta nos estudos, sobretudo os que fazem parte da geografia cultural, uma vez que esta se propõe a realizar estudos que os expliquem.

No contexto das novas tendências que emergem frente aos estudos culturais, encontramos o tema das novas linguagens disponibilizadas e transformadas continuamente às massas populacionais, se constituindo em forças de ruptura e renovação cultural do mundo contemporâneo. Desta maneira, surgem formas de análise que se adaptaram a tais tipos de linguagens próprias do pós-modernismo. Configura-se a virada lingüística que tem por meta revelar os processos culturais implícitos nas novas maneiras de ver o mundo de compreendêlo, ou pelo menos chegar o mais próximo disso.

No âmbito geográfico a virada lingüística está tomando forma e buscando conquistar seu espaço. Diversos autores em geografia cultural já têm tomado a liberdade de publicar textos que tratam desta nova postura frente aos processos culturais transformados, abrangidos pelas tendências atuais e demonstrado seu encantamento face aos instigantes temas levantados na atualidade, colocando suas primeiras manifestações na interpretação dos signos e seus significados, nas linguagens que se tornam cada vez mais globais.

Entre o certo e o incerto o que é fato dentro destas perspectivas é a presença indiscriminada de temas e assuntos distintos dos que se tinha anteriormente, sobretudo a partir dos anos 1990, quando tem início a trajetória que ganha o nome de virada linguiística, que como o próprio nome já nos diz, promete uma reviravolta epistemológica da geografia cultural. Tal fato leva a crer que novamente somos tomados por uma latente necessidade de 
engajamento em discussões. Como nos diz o título do artigo de Gonçalves (1982) "A geografia está em crise. Viva a geografia!”.

\section{REFERÊNCIAS}

AMARAL JR., A. Tecnologia, experiência e memória. Liine em revista, v. 1, $\mathrm{n}^{\mathrm{o}} 2$, setembro 2005, p. 71-82. Disponível em: HTTP://www.ibiet.br/liine

CLAVAL, P. A geografia cultural: o estado da arte. Reproduzido em: ROSENDAHL, Z. \& CORRÊA, R. L. Manifestações da cultura no espaço. Rio de Janeiro: EDUERJ, 1999.

b. A geografia cultural. Tradução de Luiz Fugazzola Pimenta e Margareth de Castro A. Pimenta. Florianópolis: Ed. Da UFSC, 1999.

CORRÊA, R. L. Geografia cultural: passado e futuro - uma introdução. Reproduzido em: ROSENDAHL, Z. \& CORRÊA, R. L. Manifestações da cultura no espaço. Rio de Janeiro: EDUERJ, 1999.

CORRÊA, R. L. Trajetórias geográficas. $3^{a}$ ed. Rio de Janeiro: Bertrand Brasil, 2005.

COSGROVE, D. A geografia está em toda a parte: cultura e simbolismo nas paisagens humanas. Reproduzido em: CORRÊA, R. L. \& ROSENDAHL, Z. Paisagem, tempo e cultura. Rio de Janeiro: EDUERJ, 1998.

Mundos de significados: geografia cultural e imaginação. Reproduzido em: CORRÊA, R. L. \& ROSENDAHL, Z. Geografia Cultural: um século (2). Rio de Janeiro, EDUERJ, 2000.

COSGROVE, D. \& JACKSON, P. Novos rumos da geografia cultural. Reproduzido em: CORREAA, R. L. \& ROSENDAHL, Z. Introdução a Geografia Cultural. Rio de Janeiro: EDUERJ, 2003.

DUNCAN, J. A paisagem como sistema de criação de signos. Reproduzido em: CORRÊA, R. L. \& ROSENDAHL, Z. Paisagens, textos e identidades. Rio de Janeiro: EDUERJ, 2004.

FERRARA, L. D’A. Ver a cidade: cidade, imagem, leitura. São Paulo: Nobel, 1998.

HAESBAERT, R. Territórios alternativos. Niterói: EdUFF; São Paulo: Contexto, 2002.

SAHR, W. G. J. D. Linguagem, imagem e o performativo: Um tour d'horizon na Nova Geografia Cultural. Palestra proferida no l Colóquio Nacional do NEER. Curitiba, 2005. Disponível em: HTTP://www.invencionweb.com.br/neer/mesas

SILVA, A. Imaginários urbanos. São Paulo: Perspectiva; Bogotá, Col: Convênio Andres Bello, 2001.

SOJA, E. Geografias pós-modernas: a reafirmação do espaço na teoria social crítica. Tradução de Vera Ribeiro. Rio de Janeiro: Jorge Zahar Editor, 1993.

\section{BIBLIOGRAFIA CONSULTADA}

COELHO NETO, J. T. Semiótica, Informação e Comunicação. São Paulo: Perspectiva, 1983. 
HALL, S. A identidade cultural na pós-modernidade. $8^{\mathrm{a}}$ ed. Tradução de: Tomaz T. da Silva e Guacira Lopes Louro. Rio de Janeiro: DP \& A, 2003.

HARVEY, D. A condição pós-moderna. São Paulo: Loyola, 1993.

SAHR, W-D. A Semiótica da Espacialização na Geografia Cultural. In: KOZEL, S.; SILVA, J. da C.; GIL FILHO, S. F. Da Percepção à Representação: reconstruções teóricas da geografia cultural e humanista. São Paulo: Terceira Margem, 2007.

(Recebido em abril/08. Aceito em setembro/08) 